\title{
Effective Power Transmission by Means of Air Compressor, Air Turbine System and Solar Concentrators
}

\author{
Harikrishnan R, K.C James
}

\begin{abstract}
Usually Electrical Power is generated in large scale using Air Compressors and Gas Turbine Systems. This type of Power plants is usually used as Peak load Power Plants. These Power Plants can assist in various power generation process along with base load power plants like Thermal Power Plants, Combined cycle power plants etc. Here in this Research paper, a new method of Power generation is being discussed. It utilizes an Air Compressor-Air Turbine System for Electrical Power generation by means of effective power transmission. This method is simple and less costly. It requires less space and less skilled laborer. It can be used in Stand by and Emergency power generation systems. An ANN model is carried out which gives satisfactory working conditions. The cost analysis is being carried out by considering small capacity and micro power production conditions. The efficiency attained during this method of power generation is around $55 \%$. By incorporating large macro energy systems, we can produce more power output and also generate more electrical power. By considering all these factors it can be considered as a very good working model.

Keywords: Air Turbine, Air Compressor, Electrical Power, ANN, Input Power, Output Power, Effective Power Transmission, Power Plants
\end{abstract}

\section{INTRODUCTION}

$\mathrm{U}_{\mathrm{s}}$ sually in all Compressor- Gas Turbine systems, gaseous fuel is being used for Compression process and Expansion process. The gaseous fuels are becoming rare and rare in this Universe due to its scarcity in the nature. Also it needs a fuel combustion system and is costlier in the working conditions. If instead of this; air which is abundantly available in the nature is used for the above conditions; it is very cheap and simpler in operation. This particular research paper aims at improving the efficiency and producing high work output by the use of air which is being heated and supplied using a blower. By this method there is considerable reduction of cost which can be achieved in the Electrical power production. This method is very simple and can easily perform with continuous working conditions. It is a very eco friendly electrical power production process. Here $10 \%$ of the power produced during the Air Turbine expansion process is utilized for driving the air compressor.

Manuscript received on March 23, 2021.

Revised Manuscript received on June 23, 2021.

Manuscript published on June 30, 2021.

* Correspondence Author

Harikrishnan R*, Research Scholar Cusat \& Assistant Professor, Department of Mechanical Engineering, College of Engineering and Management Punnapra, Alappuzha (Kerala), India.

Dr. K.C James, Professor, Department of Statistics, College of Engineering and Management Punnapra, Alappuzha (Kerala), India.

(C) The Authors. Published by Blue Eyes Intelligence Engineering and Sciences Publication (BEIESP). This is an open access article under the CC BY-NC-ND license (http://creativecommons.org/licenses/by-nc-nd/4.0/)

\section{Important Components in the Power Transmission} System

1. Air Cylinder

2. Heating unit

3. Blower

4. Air Compressor

5. Air Turbine

6. Shaft

7. Generator

8. Step up Transformer

9. Power grid lines

10. Heat Exchanger

11. Solar Concentrators

Here the blower used is electric blower fan. The compressor used is having light weight and is simple in operation. The material of compressor is of light metal alloy or non corrosive type material (alloy of aluminium). It is of a centrifugal type compressor.

At the inlet of the compressor, hot air from the hot cylinder is driven in and causes the compressor vanes to rotate also. When the air falls into the casing of the compressor, it falls in the diffuser. In the compressor, the hot air is compressed due to rotation of the impeller. The impeller rotates at high speed around $25000 \mathrm{rpm}$. When this high velocity air passes through the diffuser, its velocity first decreases and later the pressure increases. This type of compressor is used to supply air at a pressure ratio around 4. The reduction in the kinetic Energy of air in the diffuser is converted into pressure energy of air. Nearly half of the compression is achieved in the impeller and half in the diffuser. The compression process is isothermal and the temperature is maintained constant by supplying hot air at very high temperature and is continuously supplied.

Air turbine is also made up of light metal alloy. Turbine blades are made up of Alloy of Aluminum. Air Compressor and Air Turbine are directly coupled together using a Flanged coupling. Heating unit is hot air cylinder from where there is continuous flow of hot air at a constant elevated temperature. An electrical blower is being operated and the hot air from the hot cylinder is forced to drive over the air turbine at constant temperature. It is an isothermal expansion process.

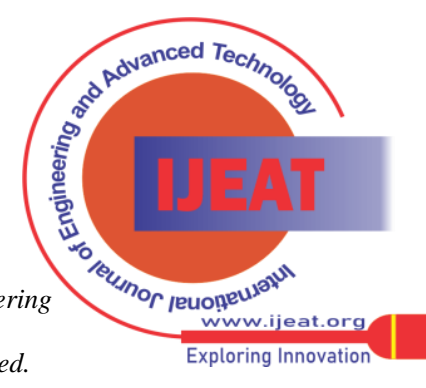



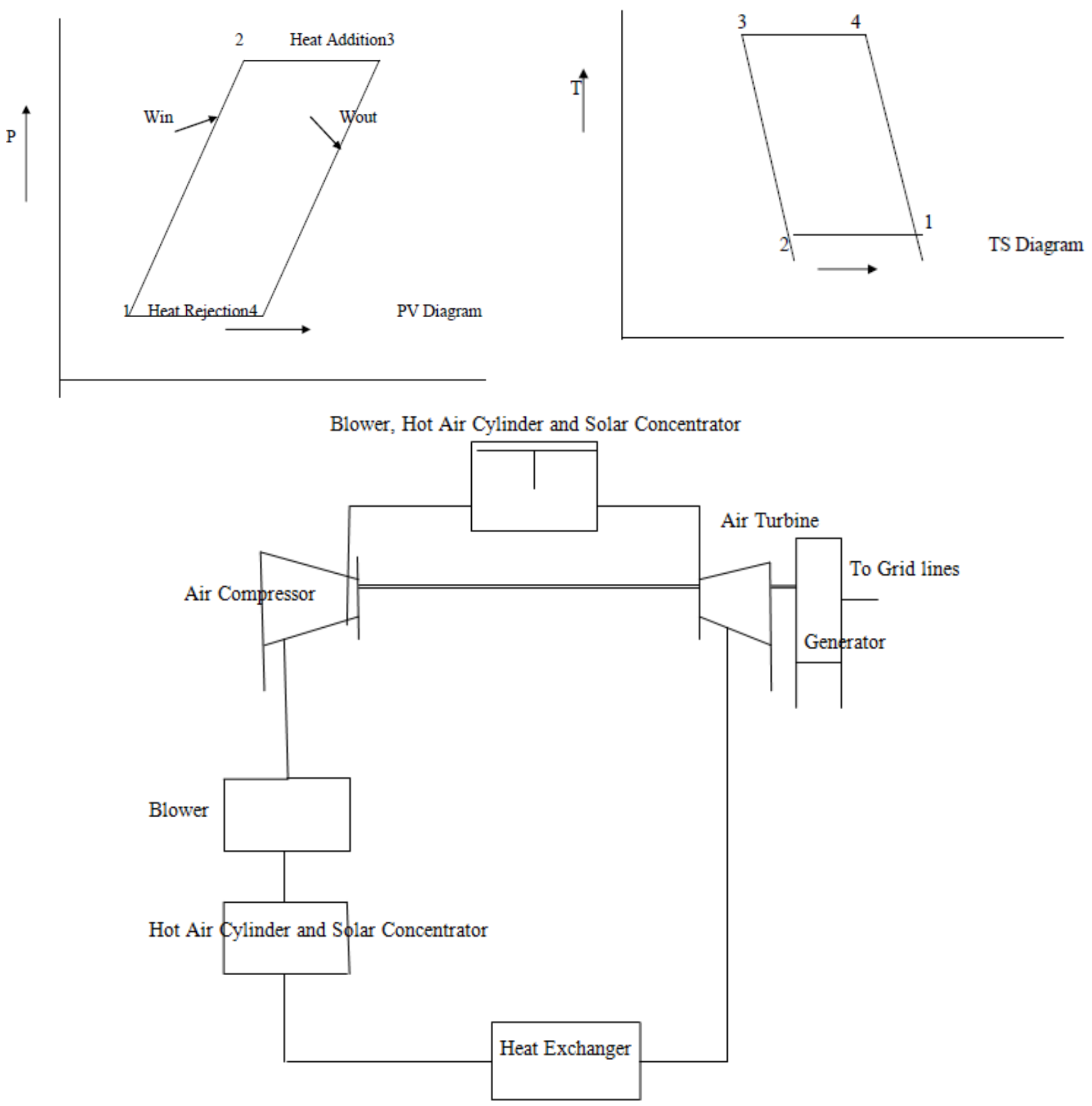

Figure 1

In all Power generation process, usually Compressors use gaseous mixture to intake heat Energy. This hot mixture of gases gives driving force to activate the motion to the Gas turbine. A fuel handling system is much costlier and also fuels are having scarcity in the nature. Here in this process, hot air is supplied from a hot air cylinder. Hot air is supplied to the Air compressor through an electric blower. Hot air is produced by concentrating light and heat from the Sun into the air cylinder using Solar Concentrators. Electric blower supplies hot air continuously into the Air compressor.

Initially the compressor is driven by an electric motor and after some time when the hot air is transferred into the Compressor system from the blower, high compression of air takes place inside the Compressor. This compression process is Isothermal compression process. The temperature of air entering into the Compressor remains same.

$\mathrm{W} 12=\mathrm{P} 1 \mathrm{~V} 1 \ln (\mathrm{V} 2 / \mathrm{V} 1)$

The above equation shows the Work done by the Compressor.

$\mathrm{P} 1=$ Inlet pressure of air

$\mathrm{V} 1=$ Inlet volume of air

V2= Discharge volume of air

The air enters into the blades axially and passes out radially. The light metal blades are about to revolve at high rpm, when the hot air falls on the blades. Through the regular supply of air from the hot air cylinder helps to maintain the constant temperature during the compression process.

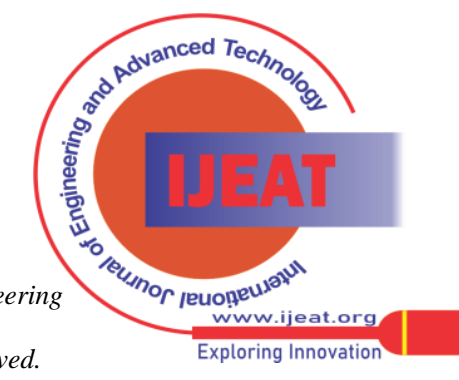


The hot air driven out of the compressor is again mixed up with hot air from the hot air cylinder and is supplied into the turbine through a blower. This large quantity of hot air falls on the Air turbine. Air turbine blades are also made up of light material. When the hot air falls on the Air turbine blades, it began to rotate with some rpm. This expansion process is also isothermal process. This is because the temperature remains same during the expansion process.

W34=P3V3ln(V4/V3)

Net Work done $=\mathrm{P} 3 \mathrm{~V} 3 \ln (\mathrm{P} 3 / \mathrm{P} 4)-\mathrm{P} 1 \mathrm{~V} 1 \ln (\mathrm{P} 2 / \mathrm{P} 1)$

Efficiency $=$ Net work done $/$ heat supplied $=(\mathrm{P} 3 \mathrm{~V} 3 \ln (\mathrm{P} 3 / \mathrm{P} 4)-\mathrm{P} 1 \mathrm{~V} 1 \ln (\mathrm{P} 2 / \mathrm{P} 1)) / \mathrm{mR}(\mathrm{T} 3-\mathrm{T} 2)$

Process 1-2= Isothermal compression

Process 2-3=Constant pressure heat addition

Process 3-4=Isothermal expansion process

Process 4-1= Constant pressure heat rejection

The blower used here is an electric blower. From the hot air cylinder, the electric blower supplies continuous supply of hot air. The temperature of air supplied is around $200^{\circ} \mathrm{C}$. This temperature of air is attained by using solar concentrators and a concentrating sunlight. The shaft of the turbine is connected with a generator. When the armature cuts the line of flux in the system, electrical power is being generated.

Voltage is amplified using the step up transformer. The step up voltage is transmitted to the $3 \varphi$ Power grid lines.

The output from the Air Turbine is being supplied to a heat exchanger and is again heated. This hot air is supplied to the hot air cylinder. The electric blower supplies air to the air compressor and the processes are repeated. The whole system is closed in operation and can be called as a closed system.

Ten percent of the electrical energy generated in the generator is utilized to drive the compressor using an electric motor.

\section{ESTIMATED COST ANALYSIS}

Compressor system- Rs.25000

Turbine system-Rs. 25000

Heat Exchanger-Rs.5000

Blower-Rs.6000

Hot Air Cylinder-Rs.4000

Generator-Rs.25000

Step up Transformer-Rs.10000

Solar Concentrator-Rs. 10000

Total estimated cost-Rs.1,10,000

\section{SAMPLE CALCULATION}

Work done during Expansion process $=8.314 \times 300 \times \ln 4$ $=3.47 \mathrm{~kW}$

Work done during Compression process $=8.314 \times 150 \times \ln 4$ $=1.733 \mathrm{~kW}$

Heat Supplied from a constant heat system $=8.314 \times 400$ $=3.326 \mathrm{~kW}$

Efficiency of this system $=(3.47-1.733) / 3.326=52 \%$

\section{ARTIFICIAL NEURAL NETWORK MODEL}

TABLE: 1

\begin{tabular}{|c|c|c|c|c|}
\hline $\begin{array}{c}\text { Output } \\
\text { Power } \\
\text { Produced }\end{array}$ & $\begin{array}{c}\text { Input } \\
\text { Power } \\
\text { Watts }\end{array}$ & $\begin{array}{c}\text { Net Work } \\
\text { Done/sec } \\
\text { Watts }\end{array}$ & $\begin{array}{c}\text { Efficiency } \\
(\%)\end{array}$ & $\begin{array}{c}\text { Cost of } \\
\text { Power } \\
\text { Generation } \\
\left(\times 10^{\wedge} 6\right) \text { in } \\
\text { Rs }\end{array}$ \\
\hline 1750 & 3500 & 1750 & 50 & 1 \\
\hline 1820 & 3345 & 1525 & 46 & 0.92 \\
\hline 1900 & 3200 & 1300 & 41 & 0.9 \\
\hline 2200 & 3000 & 800 & 27 & 0.85 \\
\hline 1400 & 3000 & 1600 & 53 & 1.1 \\
\hline 1450 & 3300 & 1850 & 56 & 1.3 \\
\hline 1850 & 4000 & 2150 & 54 & 1.1 \\
\hline
\end{tabular}

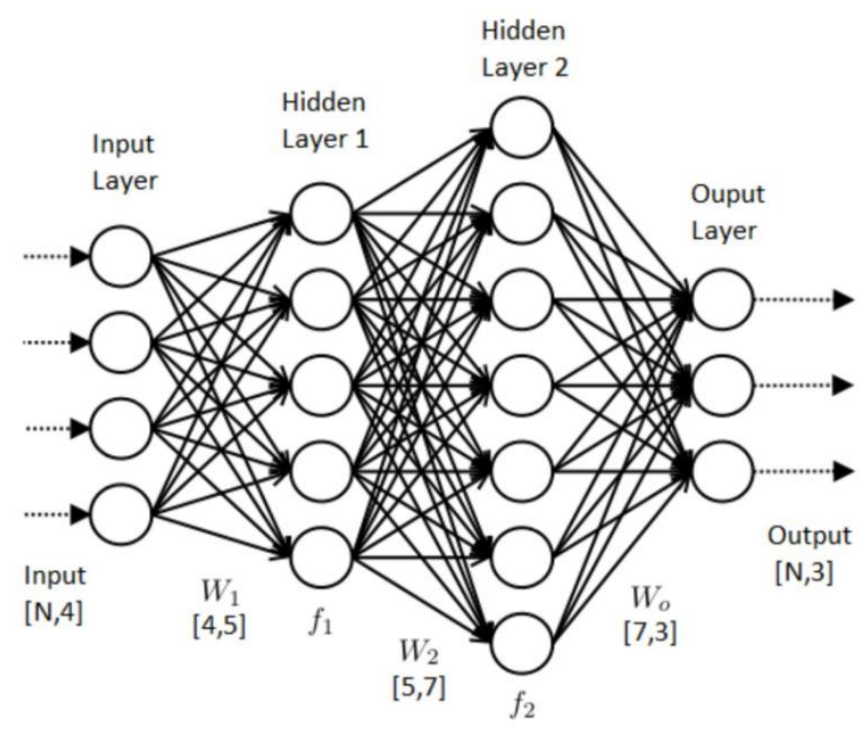

Figure2:ANN

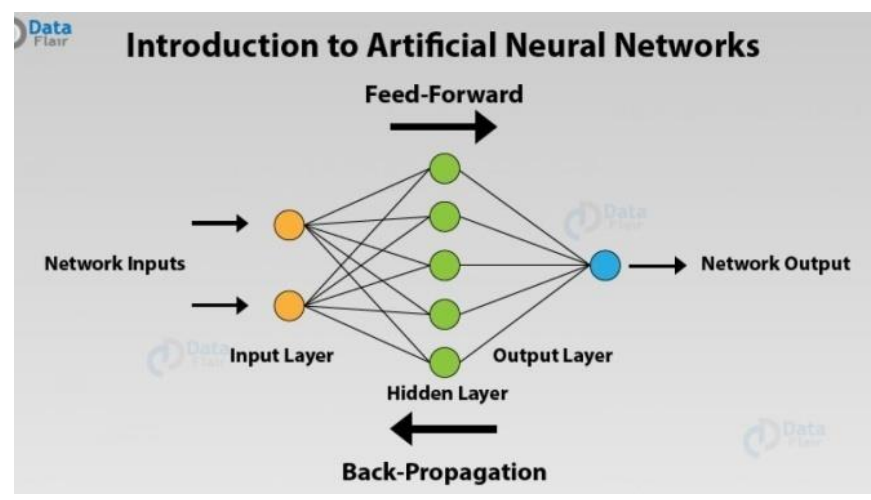

Figure3: ANN

The Neural network model is

$\mathrm{I}=\Sigma \mathrm{WiXi}+\mathrm{Bk}$

$\mathrm{I}=\mathrm{W} 1 \mathrm{X} 1+\mathrm{W} 2 \mathrm{X} 2+\mathrm{W} 3 \mathrm{X} 3+\ldots \ldots . .+\mathrm{WnXn}$

$\mathrm{I} 1=0.5 \mathrm{X} 1+0.46 \mathrm{X} 2+0.41 \mathrm{X} 3+0.27 \mathrm{X} 4+0.53 \mathrm{X} 5+0.56 \mathrm{X} 6+0.54$

$\mathrm{X} 7$

$\mathrm{I} 2=0.85 \mathrm{X} 1+0.82 \mathrm{X} 2+0.78 \mathrm{X} 3+0.73 \mathrm{X} 4+0.73 \mathrm{X} 5+0.80 \mathrm{X} 6+0.98$

$\mathrm{X} 7$

$\mathrm{I} 3=0.76 \mathrm{X} 1+0.79 \mathrm{X} 2+0.83 \mathrm{X} 3+0.96 \mathrm{X} 4+0.61 \mathrm{X} 5+0.76 \mathrm{X} 6+0.80$ $\mathrm{X} 7$

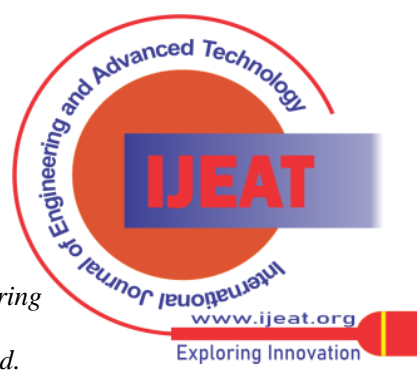


$\mathrm{I} 4=0.77 \mathrm{X} 1+0.71 \mathrm{X} 2+0.69 \mathrm{X} 3+0.65 \mathrm{X} 4+0.85 \mathrm{X} 5+\mathrm{X} 6+0.85 \mathrm{X} 7$

$\mathrm{Bk} 1=1$

$\mathrm{Bk} 2=0.9575$

$\mathrm{Bk} 3=0.8$

$\mathrm{Bk} 4=0.75$

Here we can undertake relationship between functions and its variables.

I1 is a function of $(\mathrm{I} 2+\mathrm{I} 3+\mathrm{I} 4)$

Where I1 is the independent variable which is the Efficiency of Power generation and I2, I3 \&I4 are respectively dependent variables viz. Input Power, Output Power and Cost of Power generation.

Inputting $\quad \mathrm{X} 1, \mathrm{X} 2 \ldots . . \mathrm{X} 7=0.1,0.2,0.4,0.6$ and 1 consecutively 14.96 .

On solving we get values as 2.85, 4.1975, 6.89, 9.67 and

Dividing by 50 , we get values as

$0.057,0.084,0.1378,0.1928$ and 0.2992

Therefore input values are $0.1,0.2,0.4,0.6$ and 1 .

The output values are $0.057,0.084,0.1378,0.1928$ and 0.2992 .

The Obtained value is

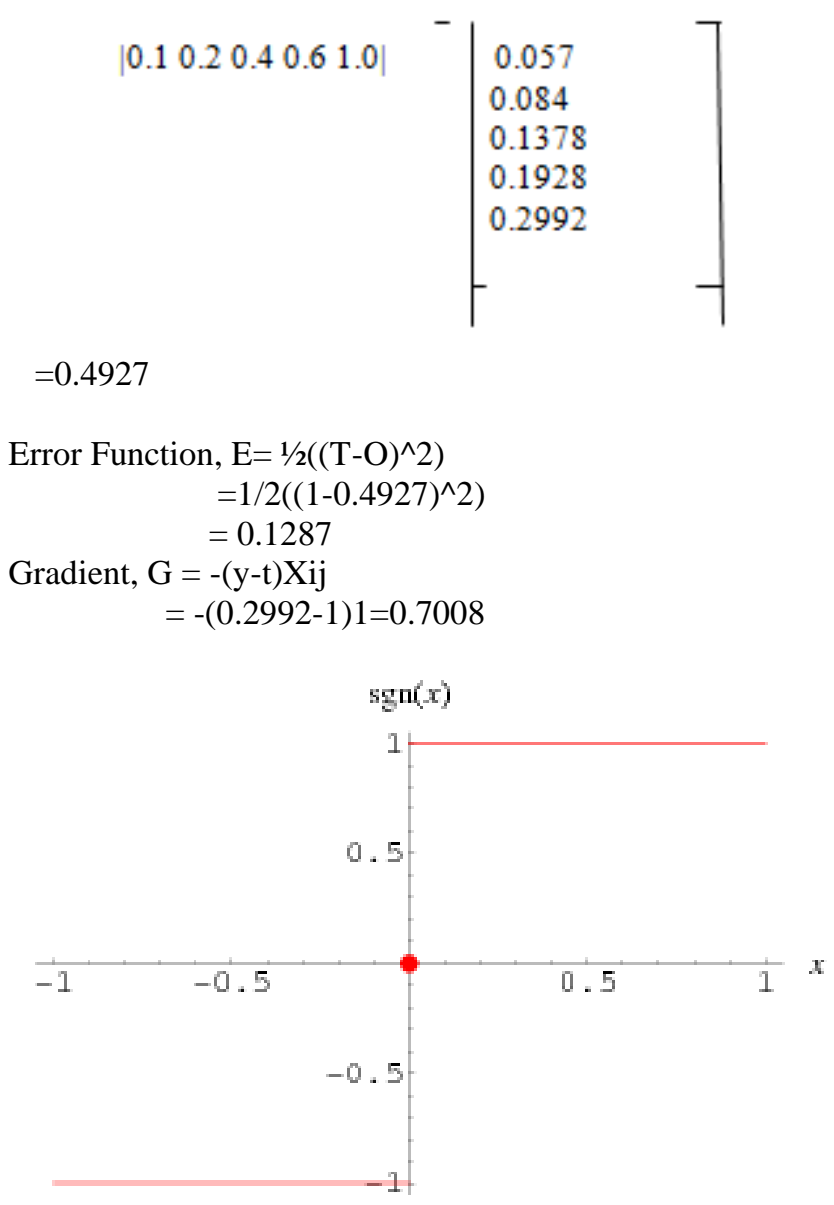

Figure: 4 Signum Function

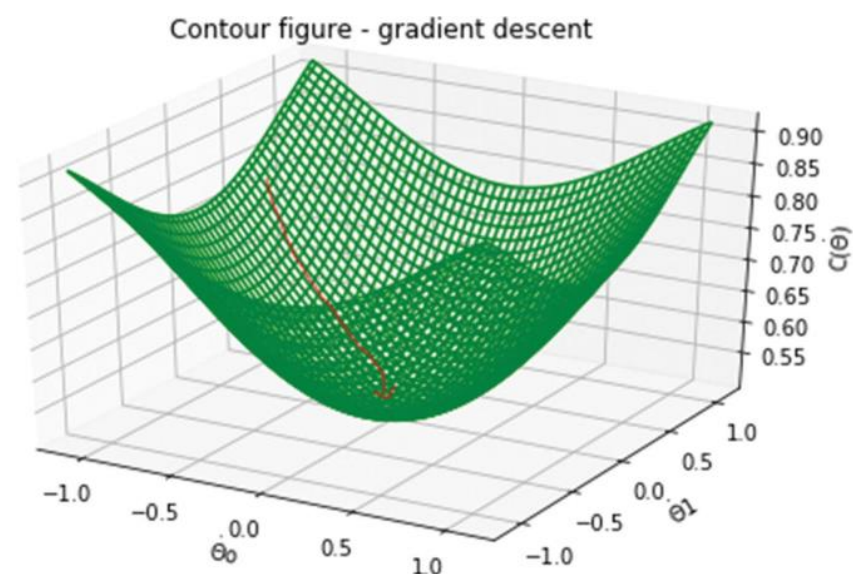

Figure 5: Gradient Descent

\section{CONCLUSION}

This is very low cost method of Electrical Power generation. The efficiency of the system is more than $50 \%$. It is a continuous power generation process. It needs only hot air which is abundantly available in the nature itself. It is not depleting and has no harmful effects. It is simple in operation and can work with a less skilled laborer. The operating cost and the maintenance cost is low. There is little wear and tear. The air used is non toxic and non inflammable. Large quantities of air can be available at any time when needed. It produces high Power output from the Compressor and Turbine system. The optimization of the working model with ANN is also giving satisfactory results. It is very easy to handle and requires less space. From the above facts, this particular Electrical power generation system can be used under any operating conditions at low cost.

\section{REFERENCES}

1. Online Model Recursive Identification for Variable Parameters of Driveline Vibration: Pelin Dai, Ying Huang,DinghaoHao,Ting Zhang, SAE International,2017-01-2428

2. Optimization of Vibration Performance and Emission of C.I Engine OperatedonSinarouba Bio diesel using Taguchi and multiple Regression Analysis: Dnyaneshwar. V.KadamSangram.D.Jadhav SAE International,2017-01-2137

3. Measurement of Engine Vibrations with a fuel blend of Recycled lubricating Oil andDieselOil:Marcos Gutierrez, Andres Castillo, Juan Inignez, Gorkey Reyes, SAE International,2017-01-2333

4. In-Plane and Out of Plane Vibrations of Brake linings on the rotor: Georg Peter Ostermeyer,JohannesOtto,Seong Kwan Rhee,SAE International,2017-01-2530

5. Systematic Experimental Creep Groan Characterization using a Suspension and Brake Test Rig:ManuelPurscher,Peter Fischer, SAE International,2017-01-2488

6. Reduction of Driveline Boom Noise and vibration of 40 seat Bus through Structural Optimization: Jose Frank,SohinDoshi,Manchi Rao, Prasath Raghavendran, SAE International,2017-28-1926

7. Theory of Machines: R.S.Khurmi, J.K.Gupta, S.Chand Publications

8. The Condition Monitoring of Rolling Element Bearings using Vibration Analysis: J.Mathew and R.J.Alfredson, ASME Journal,447-453,July01,1984

9. Mechanical Vibrations: Singires S Rao, Pearson Education India

10. Text Book of Mechanical Vibrations: Rao. V.Dukkipati, J.Srinivas, PHI Publications
Blue Eyes Intelligence Engineering and Sciences Publication

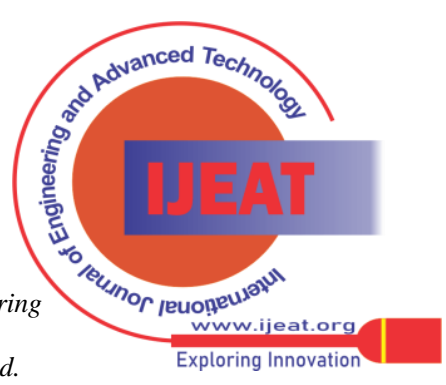


11. Arundhati Garad and Prof. V. J. Shinde. A Theoretical Model of Deep Groove Ball Bearing for Predicting the Effect of Localized Defects on Vibrations. International Journal of Mechanical Engineering and Technology, 8(6), 2017, pp. 760-769.

12. D. Rajesh, V. Balaji, A. Devaraj and D. Yogaraj. An Investigation on Effects of Fatigue Load on Vibration Characteristics of Woven Fabric Glass/Carbon Hybrid Composite Beam under Fixed-Free End Condition using Finite Element Method. International Journal of Mechanical Engineering and Technology, 8(7), 2017, pp. 85-911.

13. High-Precision Modeling of Heat exchanger Core on Vehicle Engine Room Airflow Analysis: Sinya Miura, Takashi Yasuda dated 2017. 03-28;SAEInternational

14. A Thermal Bus for Vehicle Cooling Applications-Design and Analysis: Shervin ShoaiNaini, Junkui(Allen)Huang, Richard Miller, John R Wagner, Denise Rizzo, Scott Shurin, Katherine Sebeck dated 28-03-2017;SAE International

15. Evaluation of Heat Pipe Heat Exchanger for Automotive Applications: Alaa El-Sharkawy, Ahmed Uddin, SAE International

16. Scaling Model of Heat Exchangers in Automotive Air Conditioning Systems: Kaushal kumar Jha, Imran Shaik, SAE International

17. Research on and Thermal performance of the Heat Exchanger in Automotive Exhaust- Based Thermoelectric Generator: Xinyu Wang, YadongDeng,SAE International

18. A Heat Transfer Text Book by John.H.Lienhard

19. Modeling and Approximation in Heat Transfer:Leon Glicksman and John Lienhard

20. Statistical Thermodynamics: Chang-Lin Tien

\section{AUTHORS PROFILE}

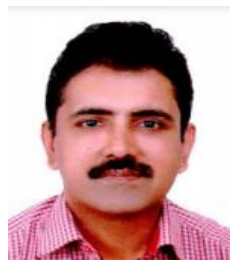

Harikrishnan Ravindranathan, Schooling had been completed in Chinmaya Vidyalaya CBSE English Medium School Pazhaveedu Alappuzha and TDHS English Medium School Alappuzha. After that College days, particularly, Pre degree from S D College Alappuzha under Kerala University, B Tech in Mechanical Engineering from LBS College of Engineering under Calicut University and $\mathrm{M}$ Tech in Energy Management from NIT Calicut. Now pursuing Part time PhD in Energy and Power Transmission Systems at Cochin University of Science and Technology. Having an overall work experience of 16.5 years as Faculty, Contract Engineer, Development Officer, Clerk, Contract Lecturer and Assistant Professor. At present working as Assistant Professor in Mechanical Engineering at College of Engineering \& Management Punnapra Alappuzha Kerala India. E-mail: harikr24jan@gmail.com

Technical Skills: Programming Skills: C, C++, VB, JAVA ASP.NET Operating System: Windows, UNIX flavors like UBUNTU Software Packages: AutoCAD, MS Office, PRIMAVERA RDBMS ORACLE, SQL

Working Experience:

1. 4 years of Experience in Teaching as Contract Lecturer in Mechanical Engineering at CochinUniversity.

2. Altogether 7 months of Experience as D.O in L I C, 9 months of experience as clerk in Government Service, 2 months in IL Palghat and in 5 months in CAD Center, Cochin.

3. At present working as Assistant Professor in Mechanical Engineering; at College of Engineering \& Management Punnapra Alappuzha Kerala India; since1/1/2011.

Blue Eyes Intelligence Engineering and Sciences Publication

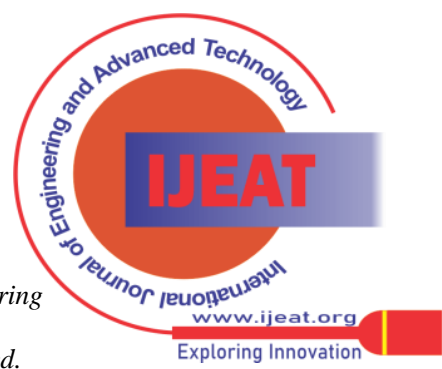

